\title{
Migrações sul-sul: a recente onda de imigrantes zimbabweanos em Tete - Moçambique (2007-2016)
}

\author{
Tomás Cebola* \\ Alisson F. Barbieri ${ }^{\star \star}$ \\ Gisela P. Zapata ${ }^{\star \star \star}$
}

O objetivo deste artigo é analisar a dinâmica das migrações internacionais sul-sul a partir do estudo de caso da recente imigração de zimbabweanos para a província de Tete, Moçambique, historicamente uma região de emigração. Nesse sentido, examinamos as características sociodemográficas desses novos imigrantes, assim como as condições e motivações individuais, familiares e estruturais subjacentes ao fluxo migratório. Para tanto, combinamos dados quantitativos provenientes do Censo moçambicano de 2007 e dos registros de trabalhadores imigrantes da Direção Provincial de Trabalho, Emprego e Segurança Social, com entrevistas semiestruturadas junto aos imigrantes zimbabweanos em Tete. Os resultados indicam uma multiplicidade de fatores que contribuíram para a recente onda de imigração em Tete, com destaque, além das motivações econômicas e de subsistência familiares, para aspectos sociais e culturais relacionados à longa tradição da mobilidade intrarregional na África Austral, facilitada por fronteiras relativamente porosas e fortes laços culturais, linguísticos e de parentesco. Discutimos, também, como a instalação de megaprojetos de mineração com capital brasileiro, em Tete, contribuiu para torná-la atrativa como destino migratório, num contexto em que se assistiam violentas ondas de xenofobia contra imigrantes na África do Sul, principal destino das migrações na região.

Palavras-chave: Migrações sul-sul. Imigração. Moçambique. Zimbabwe. Megaprojetos.

\footnotetext{
* Instituto Nacional de Estatística (INE), Tete, Moçambique (tomaspitacebola@gmail.com; https://orcid.org/0000-00016011-004X).

** Departamento de Demografia e Centro de Desenvolvimento e Planejamento Regional (Cedeplar), Universidade Federal de MInas Gerais (UFMG), Belo Horizonte-MG, Brasil (barbieri@cedeplar.ufmg.br; https://orcid.org/0000-0002-1133-1089).

*** Departamento de Demografia e Centro de Desenvolvimento e Planejamento Regional (Cedeplar), Universidade Federal de Minas Gerais (UFMG), Belo Horizonte-MG, Brasil (gpzapata@cedeplar.ufmg.br; https://orcid.org/0000-0002-8644-5160).
} 


\section{Introdução}

As migrações internacionais têm se apresentado como um dos principais fenômenos demográficos contemporâneos, com impactos importantes sobre as estruturas sociais, econômicas, políticas, culturais e demográficas tanto nos países de origem quanto nos de destino (COLEMAN, 2006). Os deslocamentos forçados constituem um subgrupo cada vez mais relevante dos fluxos migratórios internacionais, com a proporção de pessoas deslocadas aumentando de 2,5\% para 25\%, entre 1960 e 2015 (ZAPATA; GUEDES, 2019). Dados recentes da Agência das Nações Unidas para Refugiados (Acnur) estimam 70,8 milhões de deslocamentos forçados no mundo em 2018, sendo 41,3 milhões de deslocamentos internos, 25,9 milhões de refugiados e 3,5 milhões de solicitantes de refúgio (UNHCR, 2019).

Grande parte desses movimentos refere-se a movimentos sul-sul, ou seja, entre países em desenvolvimento. ${ }^{1}$ Desde 1990, os movimentos migratórios sul-sul têm crescido muito mais rápido do que os sul-norte, com um número crescente de migrantes internacionais se deslocando entre países localizados na mesma região (HUGO, 1996; ONU, 2013; IOM, 2017; UN DESA, 2019). Entretanto, a literatura sobre migrações internacionais tem consistentemente privilegiado os movimentos sul-norte, ou seja, de países em desenvolvimento para países desenvolvidos (CASTLES, 2010; JORGENSEN et al., 2019).

O objetivo deste artigo é analisar a dinâmica das migrações internacionais sul-sul a partir do estudo de caso da imigração de zimbabweanos para a província de Tete, em Moçambique. Busca-se, nesse sentido, contribuir para ampliar o entendimento sobre o movimento migratório denominado sul-sul, que vem ganhando destaque na literatura nos últimos anos (BAENINGER et al., 2018; BAKEWELL, 2009; GAGNON; KHOUDOUR-CASTÉRAS, 2012). Trata-se de um tema singular, pois ainda hoje Moçambique é entendido prioritariamente como um país de emigração (RAIMUNDO, 2011a) e permitirá uma compreensão específica das migrações intrarregionais no contexto da África Austral (Botswana, Lesoto, Moçambique, Suazilândia e Zimbabwe), dada a complexidade dos movimentos migratórios nesta região na atualidade.

Nos últimos tempos, a província de Tete em Moçambique tem sido destino de um fluxo de imigração, principalmente aquele originário de Zimbabwe (RAIMUNDO, 2011b; PATRíCIO, 2016). Este movimento está associado à crise interna que o Zimbabwe tem atravessado desde 2000, na sequência da reforma agrária, e às subsequentes sanções econômicas impostas pelos países ocidentais. Além disso, a migração para Tete começou a ganhar cada vez mais notoriedade nos noticiários do mundo devido à exploração de carvão mineral, sobretudo após a chegada da empresa brasileira Vale. ${ }^{2}$

A análise combina dados quantitativos provenientes dos microdados do Censo moçambicano de 2007 e dos registros dos trabalhadores imigrantes da Direção Provincial de Trabalho, Emprego e Segurança Social, com 40 entrevistas semiestruturadas junto aos

\footnotetext{
${ }^{1}$ Cerca de $80 \%$ dos deslocados forçados no mundo vivem em países vizinhos de seus países de origem (UNHCR, 2019).

2 Para além da Vale, estão atualmente em Tete mineradoras como: Euroasian Natural Resource Corporation (ENRC); International Coal Venture Ltda. (ICVL) que substituiu a Rio Tinto; Jindal Coal Mining Ltda.; Capital Resource, entre outras.
} 
imigrantes zimbabweanos em Tete, realizadas entre janeiro e fevereiro de 2017. A análise foi baseada nas seguintes questões relacionadas ao objetivo do artigo: quem são esses imigrantes recentes? Quais são as características socioeconômicas e demográficas desses imigrantes? Quais as motivações que levam os zimbabweanos a se mudarem para Tete? Qual o papel dos fatores linguísticos, sociais e culturais neste fluxo migratório?

0 artigo está dividido em cinco seções, além dessa introdução. A primeira traz uma revisão histórica das migrações em Moçambique e Zimbabwe, seguida por uma revisão da literatura sobre migrações internacionais com foco nos movimentos sul-Sul. Posteriormente é descrita a metodologia e são discutidos os resultados obtidos. Por fim, são apresentadas as considerações finais do artigo.

\section{Contexto e histórico dos movimentos migratórios em Moçambique e Zimbabwe}

Moçambique situa-se ao sudeste da África e conta com uma superfície de $800 \mathrm{mil} \mathrm{km²}$ e uma população recenseada em 2007 de 20.632.434 habitantes, com projeção de 27.128.530 pessoas, para 2017. A província de Tete está localizada na região central, em um território de $100.724 \mathrm{~km}^{2}$, com população recenseada em 2007 de 1.807 .485 habitantes. Conforme o Censo de 2007, 13,7\% da população de Tete residia nas áreas urbanas e $86,3 \%$ nas áreas rurais (INE, 2007). A província de Tete faz fronteira com três países: Malawi, Zâmbia e Zimbabwe (Figura 1).

Em contraste às províncias da parte sul do país, que historicamente mantiveram um fluxo migratório com a África do Sul, Tete tem uma ligação histórica secular com o Zimbabwe, em função da proximidade geográfica, da similaridade linguístico-cultural e das trocas comerciais entre os povos, antes mesmo da presença europeia ou de quando foram traçadas as fronteiras que separam Moçambique do Zimbabwe, durante a Conferência de Berlim em 1885. ${ }^{3}$ Esta convivência e similaridade entre os povos de Tete e do Zimbabwe permitiram que, nos momentos críticos vividos em Moçambique, tais como guerras, secas e fome, os moçambicanos de Tete se refugiassem no Zimbabwe.

O Zimbabwe foi uma das mais desenvolvidas colônias britânicas na África (Rodésia do Sul). Diferentemente das outras colônias de exploração (como Quênia, Zâmbia e Malawi), a então Rodésia foi uma colônia de povoamento e, portanto, um território governado em regime de autonomia pela minoria branca desde 1923, tornando-se um polo de grande progresso da agricultura e da indústria de mineração durante a Segunda Guerra Mundial. De fato, para além de ter enviado milhares de homens diretamente para os campos de batalha, o Zimbabwe foi uma das principais fontes de fornecimento de minerais essenciais, como cromo, asbesto, volfrâmio (conhecido no Brasil como tungstênio) e mica, e de alimentos como milho, carne e tabaco para as tropas aliadas (MINTER; SCHMIDT, 1988; MLAMBO, 2009). Outro momento marcante do desenvolvimento da economia da colônia

\footnotetext{
${ }^{3}$ Em 1885, ano da realização da Conferência de Berlim, foi feita a partilha do continente africano pelos europeus. Em 1891, ano do tratado Luso-Britânico, foi determinada a fixação da fronteira entre Moçambique e Zimbabwe.
} 
rodesiana foi o período da constituição da federação das Rodésias e Niassalândia (19531960), que beneficiou e acelerou a industrialização da região. Verificou-se também, nesse mesmo período, uma significante melhoria de infraestruturas de grande envergadura, tais como o projeto da hidroelétrica da Kariba no rio Zambeze e a construção de caminho de ferro ligando o porto de Maputo ao Zimbabwe, passando por Limpopo (CEBOLA, 2010; MACKINTOSH, 1986; DAS NEVES, 1991; MLAMBO, 2005; ROBERTS, 1981).

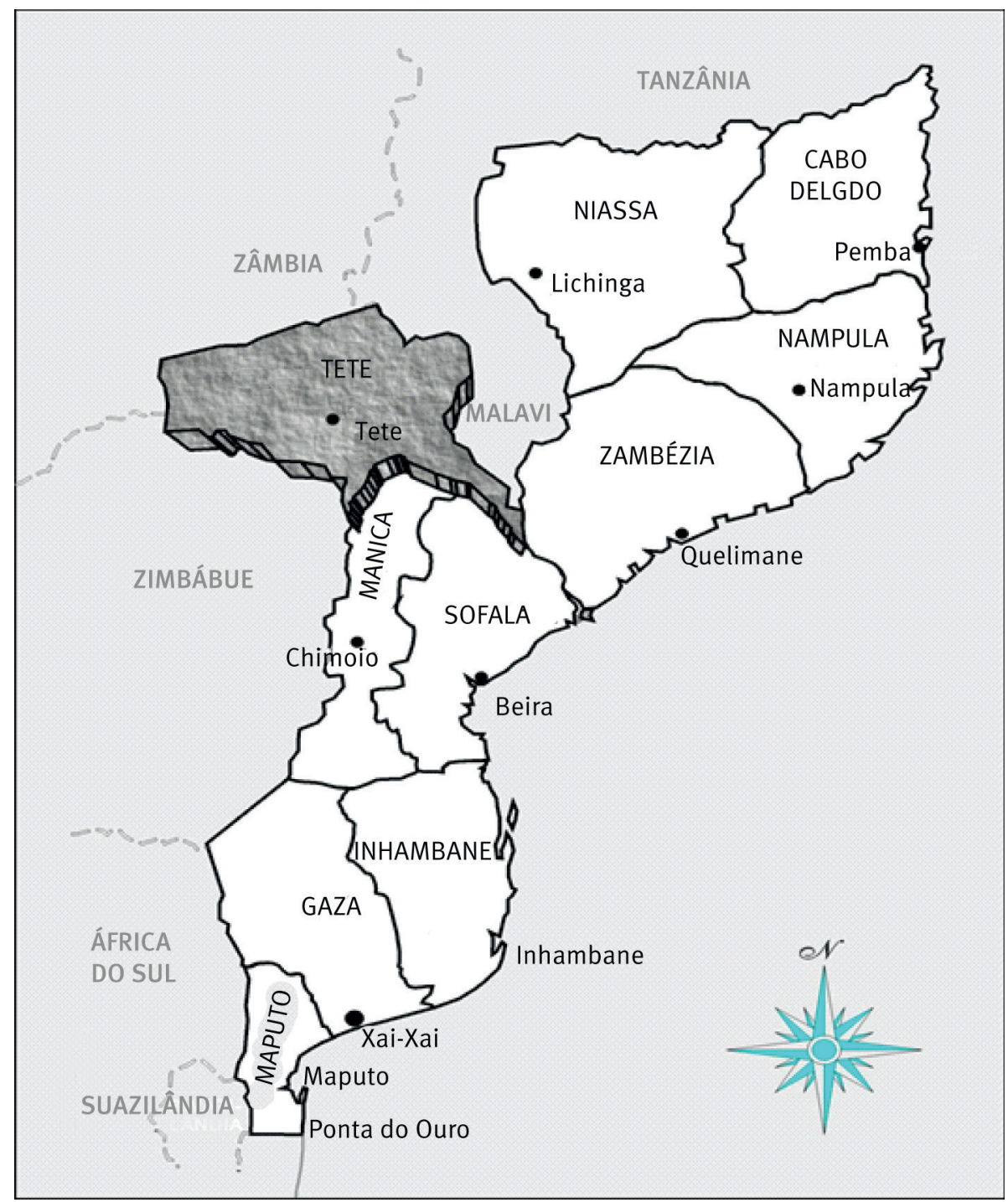

Fonte: Instituto Nacional de Estatística (INE, 2007). 
Este contexto impulsionou a emigração dos moçambicanos da região central, particularmente os de Tete, que procuravam escapar do recrutamento obrigatório e do trabalho forçado. 0 incremento da emigração de Tete, que já era oficialmente uma espécie de reserva de mão de obra para o Zimbabwe desde $1913,{ }^{4}$ se deu não só pela sua localização geográfica (cercada por colônias britânicas), mas também pelo seu débil desenvolvimento econômico e pelas grandes afinidades culturais com os povos vizinhos (DAS NEVES, 1991). Com uma grande área semiárida e por conseguinte vulnerável a secas frequentes e prolongadas, a província de Tete foi também um dos palcos mais usados pelas duas sangrentas guerras que Moçambique vivenciou. A guerra colonial (1964-1974) e a guerra civil (1977-1992) forçaram uma parte considerável da população a se refugiar nos territórios vizinhos, entre eles o Zimbabwe. Os refugiados só retornaram em massa ao país após a assinatura do Acordo Geral da Paz, em 4 de outubro de 1992, entre a Resistência Nacional de Moçambique (Renamo) e o governo da Frente de Libertação de Moçambique (Frelimo). A província de Tete recebeu cerca de 790.000 retornados (PATRÍCIO, 2016).

A partir dos anos 2000, com a eclosão da crise sociopolítica e econômica interna no Zimbabwe na sequência da reforma agrária, começou a se verificar o movimento contrário: a vinda dos vizinhos zimbabweanos a Tete em busca de oportunidades, paz e tranquilidade. A economia de Moçambique, e da província de Tete em particular, tem sido dominada, desde 2007, por megaprojetos de mineração, recebendo investimentos iniciais superiores a USD 500 milhões (MOSCA; SELEMANE, 2011) e provocando uma onda de imigração interna e internacional.

Estes investimentos se inserem na dinâmica de expansão da presença dos países Brics (Brasil, Rússia, Índia, China e África do Sul) na África nas últimas décadas, visando a exploração do enorme potencial do continente em termos de recursos naturais, mercado de consumo e desenvolvimento econômico. Por exemplo, apesar da queda no volume do investimento estrangeiro direto (IED) na África, o IED da China no continente aumentou de US\$ 1,44 bilhão em 2009 para US\$ 2,52 bilhões em 2012; a parceria Índia-África tem promovido o desenvolvimento de empresas pequenas e médias, enquanto Brasil e Rússia têm investido fortemente na indústria de mineração e energia no continente ${ }^{5}$ (AFDB, 2013; OKOLO; AKWU, 2016). A presença dos Brics na África, especialmente da China, também tem ocorrido pela crescente cooperação sul-sul para o desenvolvimento, na forma de assistência, investimentos em infraestrutura e transferência de conhecimento e tecnologia. Ainda que o papel preeminente da China na África, especialmente em atividades agrícolas, extrativistas e projetos de infraestrutura em grande escala, possa ser visto como uma nova forma de colonialismo (GARCIA, 2017; LUMMUMBA-KASONGO, 2011), algumas pesquisas

\footnotetext{
${ }^{4} \mathrm{Em} 1913$, foi assinado o primeiro acordo formal sobre a migração de mão de obra moçambicana (Tete) para a Rodésia do Sul, entre as autoridades portuguesas e as rodesianas.

${ }^{5}$ Vale a pena ressaltar que as relações da China e da Rússia com a África são de longa data e se remetem ao apoio às guerras de independência de vários países do continente e à disputa política e ideológica entre estas potências no contexto da Guerra Fria. Por exemplo, o governo da Frelimo recebeu ajuda tanto da Rússia como da China durante a guerra civil contra a Renamo (RICH; RECKER, 2013).
} 
indicam que estes investimentos têm contribuído para melhorias nos indicadores de pobreza, segurança alimentar e saúde em países como Angola e Moçambique, ao mesmo tempo que contribuem para a visão estratégica de longo prazo da política externa chinesa (OKOLO; AKWU, 2016; ZHOU; HE, 2014).

Neste contexto, Branco (2008) estima que, de uma população de 13 milhões de habitantes, cerca de 3 milhões de zimbabweanos tenham abandonado o país após as eleições de 2008, refugiando-se em países vizinhos, nomeadamente em Botswana, África do Sul e Moçambique. Tal movimento migratório inclui não apenas os mais vulneráveis, mas também centenas de milhares de profissionais qualificados que se viram obrigados a deixar o seu próprio país (BRANCO, 2008). A esperança média de vida é um dos indicadores que mostra a gravidade da situação vivenciada no Zimbabwe. Entre 1985 e 2004, a esperança de vida declinou de 61,4 para 43,1 anos. Nos anos seguintes verificou-se uma recuperação deste indicador, atingindo 61,5 anos em 2019 (UNDP, 2019). A crise interna do Zimbabwe teve consequências negativas imediatas, múltiplas e de grande alcance, sendo uma das mais relevantes a migração forçada de milhares de pessoas para os países vizinhos.

Os pontos de passagem formais na longa fronteira terrestre que separa Moçambique do Zimbabwe são raros, e grande parte da fronteira tem sido cruzada sem controle das autoridades governamentais. Para alguns zimbabweanos que fugiram da violência político-partidário, levada a cabo pelo regime do então presidente Robert Mugabe, atravessar a fronteira significou estar fora do alcance das perseguições desse gênero. Porém, o estabelecimento de uma fronteira internacional introduz um novo conjunto de restrições e oportunidades que se tornam uma parte importante da vida das pessoas, que atravessam para evitar a tributação e a violência, obter proteção ou encontrar empregos, mercados, educação e cuidados de saúde (SKELDON, 2006). Nesse sentido, a migração se torna um problema político na medida em que condicionantes e restrições são aplicadas às pessoas que pretendem atravessar uma fronteira politicamente reconhecida.

\section{Migrações sul-sul: o contexto africano}

Diversos estudiosos têm apontado a existência de um viés na literatura sobre migrações internacionais (Northern bias), que vem relegando para segundo plano os movimentos sul-sul (CASTLES, 2010; GEIGER; PÉCOUD, 2013), ainda que, nos últimos anos, estes têm representado uma parte expressiva dos movimentos internacionais, sobretudo os de âmbito regional (HUGO, 1996; UN DESA, 2019).

Barreiras como a ausência de documentos legais para migrar, os custos da viagem, as dificuldades de arranjar emprego e atingir o status desejado no Norte, dentre outros fatores, fazem com que o principal destino das migrações envolvendo africanos na origem tenham, como destino, outro país africano. Assim, a metade dos emigrantes africanos vive em um país do continente e 9 em cada 10 africanos refugiam-se num país fronteiriço ao seu país de origem (UA, 2006; UNCHR, 2006; GUILLON, 2005). Um fator facilitador desses 
fluxos é o fato de os governos nacionais estarem administrativamente sobrecarregados com outras prioridades, fazendo com que os controles de imigração sejam muitas vezes ignorados, ou tratados, em alguns casos, sob o pretexto de preocupações de segurança nacional (GAGNON; KHOUDOUR-CASTÉRAS, 2012). A título de exemplo, os pontos de passagens formais na longa fronteira terrestre que separa Moçambique do Zimbabwe são raros e grande parte da fronteira tem sido cruzada sem controle das autoridades governamentais.

A agitação política, o conflito e outras crises que causam a fuga de pessoas são característicos da migração sul-sul, embora estes fatores inevitavelmente também desempenhem um papel nas migrações para o norte. No caso da África subsaariana, muitos movimentos em larga escala entre países são associados ao início ou ao fim de conflitos (BAKEWELL, 2009).

Outras causas relacionadas à interação entre mudanças ambientais, colapso dos meios de subsistência e fragilidade estatal também vêm sendo apontadas como responsáveis pelo crescimento dos deslocamentos sul-sul (BETTS, 2010). Nesse sentido, as migrações sul-sul também envolvem um componente econômico central, relacionado às estratégias de sobrevivência domiciliares, em que as remessas são vistas como um fator importante na redução da pobreza, facilitando o investimento das famílias e estimulando o crescimento econômico e, a nível macroeconômico, melhorando a balança de pagamentos dos países beneficiários (BILSBORROW, 2016). Estimativas recentes mostram que as remessas sul-sul podem representar de $9 \%$ a $30 \%$ da receita de remessas dos países em desenvolvimento. Não só os migrantes sul-sul tendem a ganhar menos do que os migrantes do sul-norte, mas também, em geral, os custos de envio de remessas sul-sul tendem a ser mais elevados, devido à falta de concorrência nos mercados e ao baixo desenvolvimento financeiro (RATHA; SHAW, 2007).

Vários estudos sobre as remessas enviadas por migrantes de países da África Austral para outros países da região mostraram que a maioria dos domicílios de emigrantes internacionais recebe remessas, principalmente na forma de dinheiro, de ambos os migrantes do sexo masculino e feminino (DODSON et al., 2008; PENDLETON et al., 2006; MUANAMOHA, 2010). Grande parte dessas remessas corresponde a gastos em alimentos, ou seja, uma espécie de salário para garantir a sobrevivência da família (BAKEWELL, 2009).

A essas motivações econômicas de caráter domiciliar e individual somam-se outros fatores, como a existência de rotas de migração e redes de transporte, além de laços de parentesco e redes sociais. A presença de tais redes, sem dúvida, atua como um facilitador da migração, enquanto sua ausência limitaria o movimento. Peixoto (2004) pontua que os migrantes não tendem a tomar decisões individuais, nem no ato de reflexão inicial, nem durante o próprio percurso migratório, nem nas formas de integração no destino. Eles estão inseridos em redes de conterrâneos, familiares ou, inclusive, de agentes facilitadores da migração, que fornecem a informação, as escolhas disponíveis, o apoio ao deslocamento e à fixação no destino. Assim, as redes sociais servem como pontes que ligam migrantes, antigos migrantes e não migrantes nas sociedades de origem e de destino, por meio de um conjunto de laços sociais seja de familiares, parentes, amigos e conhecidos, seja 
de integrantes das mesmas comunidades ou grupos étnicos (FAZITO, 2009; MARQUES, 2008). Existem, nesse sentido, vários fatores que contribuem para que as populações que habitam em zonas fronteiriças africanas tenham maior afinidade com sociedades de um ou mais Estados do que com outros cidadãos do seu próprio país (PATRíCIO, 2011). Nesse sentido, as migrações entre Moçambique e Zimbabwe ilustram como os laços culturais e linguísticos desempenham um papel importante, particularmente para a imigração de baixa qualificação. Os imigrantes zimbabweanos têm o shona como seu idioma principal e estão, em sua maioria, localizados no sul da província de Tete, onde as línguas dos nativos são subgrupos da língua shona, um idioma que facilita a sua integração. Tal como sublinham Jalal et al. (2010), esses laços vão além da linguagem, incluindo a religião, a alimentação, os hábitos de trabalho e os costumes familiares.

Além disso, em consonância com a tendência mundial de feminização das migrações, com o número de mulheres migrantes se duplicando entre 1960 e 2015 (DONATO; GABACCIA, 2016; GIORGULI; ANGOA, 2016), constatamos uma maior mobilidade feminina ao longo das fronteiras internacionais analisadas. No continente africano, as mulheres vêm ganhando espaço nos fluxos migratórios, com ampliação da sua participação de 42,3\% em 1965 para 47,4\% em 2005 (TOLENTINO, 2009). 0 aumento generalizado pode estar a refletir o crescimento do acesso da mulher à educação, sua maior participação nas atividades econômicas fora do agregado familiar, seu crescente empreendedorismo, assim como o aumento do tráfico de mulheres - embora este seja um fator de difícil quantificação (TOLENTINO, 2009). Como será detalhado na próxima seção, no caso específico da província de Tete, o Censo de 2007 revela que as mulheres constituem a maioria da população de imigrantes zimbabweanos em Tete. Além do mercado sexual, existe um elevado comércio interfronteiriço direto entre as províncias de Tete e Malawi e Zimbabwe, assim como entre Manica e Zimbabwe (RAIMUNDO, 2011c). Tete tornou-se também um importante mercado de trabalho para as mulheres em serviços domésticos (como observado no trabalho de campo, uma parte considerável das entrevistadas afirmou que presta serviços domésticos, em restaurantes e em casas particulares, principalmente na Vila de Luenha e em Cuchamano). A seção seguinte apresenta os dados e métodos empregados no desenvolvimento desta pesquisa.

\section{Dados e métodos}

Nosso estudo de caso combina múltiplas evidências - que se complementam - para atender aos objetivos propostos (CRESWELL, 2010). Na pesquisa quantitativa recorremos aos microdados do Censo moçambicano de 2007, que permitiram determinar a migração acumulada (Life Time Migration) - ou seja, o estoque de migrantes à data do Censo, assim como as tendências da migração mais recente com os quesitos de data fixa (cinco anos antes do censo) e data fixa próxima (um ano antes do censo) (MUANAMOHA; RAIMUNDO, 2013). O Censo permite, ainda, estabelecer o perfil sociodemográfico dos imigrantes 
zimbabweanos que se encontram na província de Tete. Ainda que os dados censitários se refiram ao universo, há problemas de enumeração de migrantes em Moçambique, devido ao fato de o Censo moçambicano não captar informações sobre emigração tanto interna como internacional, e possivelmente não contempla os imigrantes irregulares ou indocumentados.

Um segundo componente na pesquisa quantitativa envolve o uso de dados dos trabalhadores estrangeiros (zimbabweanos) na província de Tete, registrados pela Direção Provincial do Trabalho, Emprego e Segurança Social. Foram enumerados 428 trabalhadores zimbabweanos acumulados de 2007 a junho de 2017 (412 homens e 16 mulheres), distribuídos em 92 empresas ou instituições. Julgamos que esses dados são subestimados, pois os imigrantes indocumentados que trabalham em empresas formais em Tete dificilmente seriam contemplados. Tal limitação, inerente à base de dados, implica restringir a análise aos trabalhadores no mercado formal.

0 método qualitativo envolveu uma pesquisa de campo entre janeiro e fevereiro de 2017, com entrevistas semiestruturadas junto aos imigrantes zimbabweanos em quatro áreas selecionadas na província de Tete: Cidade de Tete, Vila Mineira de Moatize, Vila de Luenha e a localidade fronteiriça de Cuchamano. As áreas foram escolhidas por apresentarem alta concentração de imigrantes e pela proximidade geográfica com o Zimbabwe. 0 roteiro de entrevistas incluiu seis seções: identificação e características do entrevistado ou da entrevistada (nome, sexo, idade, status conjugal, local de nascimento, local de última residência, escolaridade, línguas faladas); 12 perguntas sobre a origem do entrevistado ou da entrevistada; 11 questões sobre a história migratória; 18 perguntas sobre a chegada e o processo de adaptação em Tete; dez questões sobre a relação com a família no local de origem; e cinco perguntas sobre planos futuros.

Foi utilizado o método de amostragem não probabilística, por ser o mais adequado para pesquisas cuja população de interesse não é totalmente conhecida e quando a sua definição precisa é problemática ou inviável. Foram realizadas 40 entrevistas semiestruturadas por meio do método bola de neve ou cadeia de referência a partir de atores-chave, cada uma com duração média de 45 minutos. Na primeira fase do estudo, identificou-se um conjunto inicial de entrevistados-chave, conhecidos na comunidade e da convivência dos imigrantes, incluindo líderes comunitários, chefes dos bairros e imigrantes zimbabweanos instalados há muito tempo no país. Na sequência, pediu-se que esses entrevistados iniciais sugerissem outros sujeitos potenciais que compartilhassem características semelhantes ou que tivessem relevância para o objeto de estudo. 0 número total de entrevistas realizadas foi sendo ajustado, uma vez que os dados coletados deixaram de produzir novas informações sobre o assunto sob investigação, ou seja, com base no conceito de ponto de saturação (GLASER; STRAUSS, 1967).

Uma dificuldade enfrentada no trabalho de campo está relacionada às operações de captura e repatriamento forçado dos migrantes indocumentados pelas autoridades governamentais de Moçambique. 0 receio de ceder informações vem dos próprios imigrantes, 
ao desconfiarem que qualquer pessoa é um potencial informante ou agente dos Serviços da Migração. Dada essa dificuldade, a estratégia utilizada foi encontrar um intermediário entre o entrevistador e cada entrevistado ou grupo de entrevistados. Nem sempre essa estratégia logrou sucesso em todos os grupos de imigrantes, como por exemplo entre as imigrantes zimbabweanas vendedoras de sexo, alojadas no conhecido mercado Kwachena ku Nyalutanda, e os imigrantes que trabalham em áreas diversas desde a venda de roupa (dentre outros produtos) até trabalhadores/as de salões de beleza e cozinheiros/as e ou serventes nos restaurantes do mercado $1^{\circ}$ de Maio na cidade de Tete.

Dada a dificuldade dos entrevistados em falar e ouvir o idioma português, grande parte das entrevistas foi feita em shona (língua africana falada pela maioria da população do Zimbabwe e cujo entrevistador era fluente). Apesar de não existir uma comissão de ética para a realização de trabalhos de campo de estudos das ciências sociais em Moçambique, o entrevistador, seguindo protocolo usual de trabalhos que incluem coleta de informações primárias no país, se apresentou às autoridades governamentais, o Governo Provincial de Tete e os governos Distritais de Changara e Moatize, e obteve autorização prévia para a coleta dos dados. A apresentação foi feita por meio de uma carta contendo os seguintes elementos: identificação do pesquisador e da instituição de ensino; objetivo e extensão da pesquisa; potencial impacto dos resultados; identificação do nível e do tipo de envolvimento dos participantes; e garantia de confidencialidade para os participantes. Não houve condições impostas à realização do trabalho de campo pelas autoridades locais. Não obstante, e seguindo parâmetros de ética em pesquisa adotados no Brasil (embora não fossem mandatórios para a pesquisa em Moçambique), antes do início da entrevista era lido um Termo de Consentimento, e os entrevistados deram consentimento verbal para a realização e gravação da entrevista. Uma cópia do TCLE assinada pelo pesquisador foi entregue aos entrevistados. Os resultados apresentados aqui foram anonimizados para proteger a privacidade e garantir a confidencialidade dos participantes. Considerando que as entrevistas foram gravadas e na sua grande parte feitas em língua shona, realizaram-se, inicialmente, a transcrição e interpretação de shona para português, a codificação e a tabulação das informações, as quais foram armazenadas em um lugar seguro - protegido com senha - e acessível somente à equipe do estudo. Em seguida, a análise e a interpretação dos dados foram feitas à luz dos objetivos e perguntas norteadoras da pesquisa.

\section{Resultados e discussão}

\section{Censo Demográfico de 2007}

Segundo o Censo de 2007, dos 20.252.223 habitantes de Moçambique, apenas 0,8\% eram estrangeiros. Grande parte destes é de nacionalidade africana, sobretudo malawiana $(49,0 \%)$, zimbabweana $(16,1 \%)$, sul-africana $(5,6 \%)$ e tanzaniana $(4,8 \%)$. Outras nacionalidades africanas, sem incluir a África Austral, representam $6,8 \%$ do total de imigrantes. 0 
Censo observou ainda que a província de Tete possui a maior concentração de imigrantes internacionais acumulados (35\%), que representam 3\% da população da Província, com participação importante de pessoas de origem malawiana $(68,2 \%)$ e zimbabweana $(18,6 \%){ }^{6}$

Ainda em relação à população estrangeira vivendo em Tete, $48,7 \%$ eram do sexo masculino e $51,3 \%$ do feminino, sendo, entre os zimbabweanos, $44,8 \%$ homens e $55,2 \%$ mulheres. 0 Censo revelou que, em 2002 (data fixa), havia 6.283 imigrantes provindos do Zimbabwe e, em 2006 (data fixa próxima), eles eram 7.905 habitantes. Grande parte dos imigrantes zimbabweanos na província de Tete corresponde a pessoas nas idades laborais de 15 a 69 anos $(65,28 \%)$.

0 Gráfico 1 representa a pirâmide etária e por sexo da população de Tete, cuja base larga mostra o caráter jovem da população: cerca de 50,3\% da sua população tem menos de 15 anos. Por sua vez, o Gráfico 2 mostra a pirâmide etária e por sexo dos imigrantes zimbabweanos. A comparação de ambos permite avaliar que grande parte dos imigrantes é composta por pessoas nas idades entre 15 e 69 anos, evidenciando, nesse último caso, um efeito de seletividade etária da migração, especialmente a laboral.

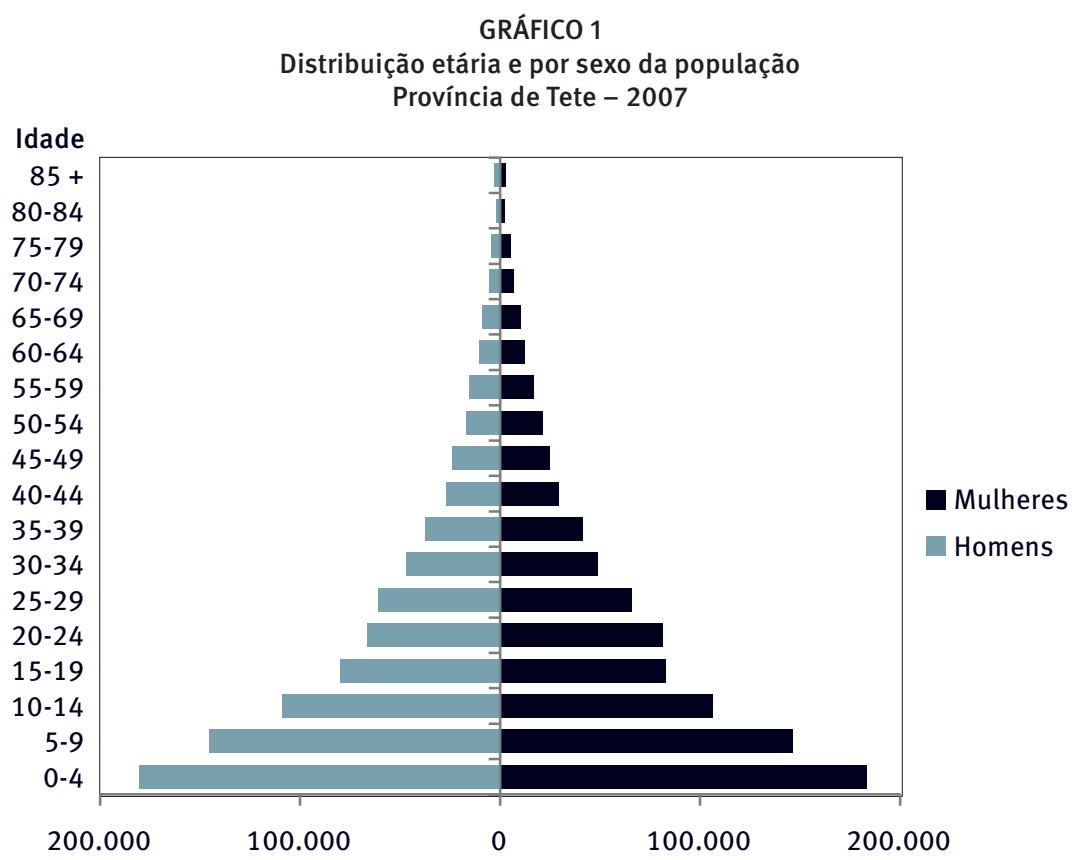

Fonte: Censo 2007, INE-Moçambique. Elaboração dos autores.

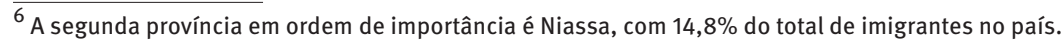


GRÁFICO 2

Distribuição etária e por sexo dos imigrantes zimbabweanos

Província de Tete -2007

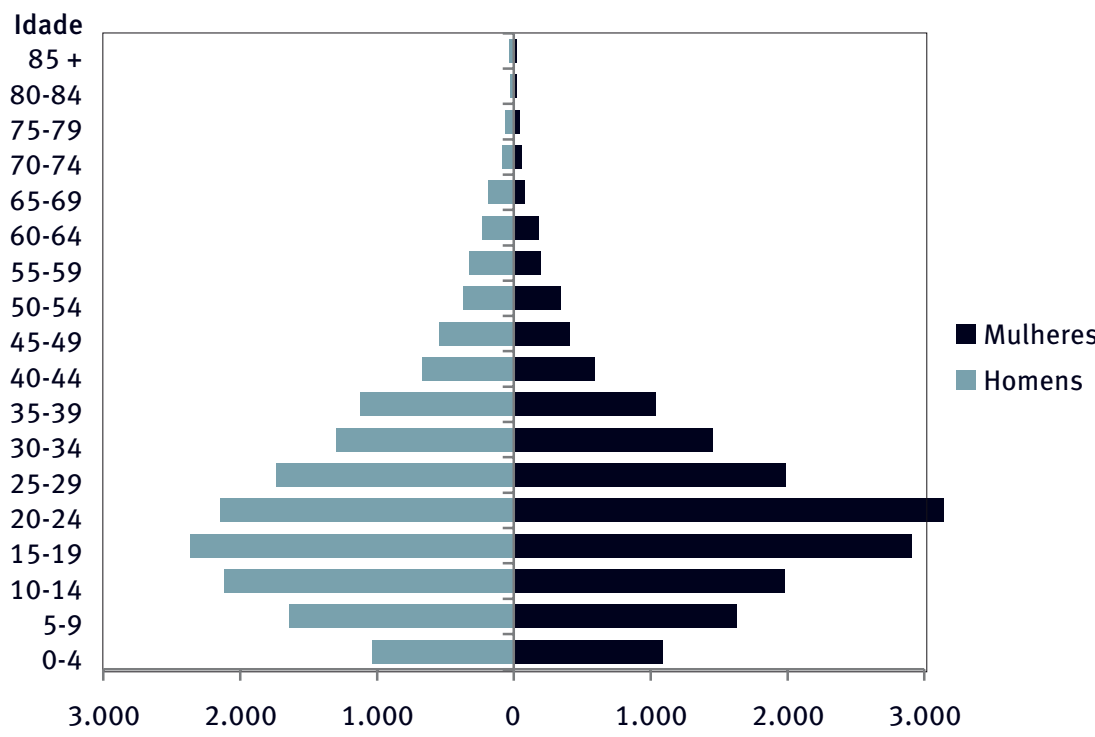

Fonte: Censo 2007, INE-Moçambique. Elaboração dos autores.

Estes resultados apontam para uma ínfima contribuição da migração internacional para o crescimento populacional na província de Tete e em Moçambique. Moçambique ainda não alcançou a transição demográfica. Em 2011, de acordo com dados do Instituto Nacional de Estatística (INE), a taxa de fecundidade total (TFT) do país era de 5,7 filhos por mulher. Na província de Tete essa taxa era de 6 filhos por mulher (INE, 2011).

Grande parte da força de trabalho na província de Tete está empregada no setor informal, com 37\% da população economicamente ativa declarando ser trabalhador por conta própria: sem empregados $(25,5 \%)$ ou trabalhador familiar sem remuneração $(11,6 \%)$. Por sua vez, o setor formal ${ }^{7}$ emprega 3,7\% da população e os restantes $59,4 \%$ estão na categoria do Censo designada "sem informação". Uma tendência similar se verifica para os zimbabweanos: $50,9 \%$ estão no setor informal, 3,9\% no setor formal e 45,1\% na categoria sem informação. Esses dados mostram claramente que o setor informal da economia domina o mercado de trabalho em Tete, sendo que essa característica é homogênea tanto para nativos como para os imigrantes. Em todos os três grupos aqui analisados, a participação masculina é superior à feminina no setor formal e esta relação se inverte no setor informal e na categoria sem informação, em que a participação das mulheres $(61,5 \%)$ é ligeiramente superior à dos homens (57,38\%).

\footnotetext{
${ }^{7} 0$ setor formal agrupa as seguintes categorias: trabalhador da administração pública; trabalhador das autarquias locais; trabalhador de empresa pública; trabalhador de empresa privada; trabalhador de cooperativa; trabalhador de instituições sem fins lucrativos; trabalhador de casa particular; trabalhador por conta própria com empregados; trabalhador de organismos internacionais/Embaixadas; e trabalhador do Censo.
} 
Em relação ao nível educacional, há predomínio da população sem nenhum nível de escolaridade concluído (58,4\% dos moçambicanos e 35,6\% dos zimbabweanos). Apesar de o número de imigrantes de sexo feminino ser maior do que o de homens, a proporção de mulheres casadas ou em união marital (52,97\%) é muito superior à dos homens nas mesmas categorias (34,97\%). A proporção de imigrantes de sexo masculino solteiros é muito maior do que a de imigrantes do sexo feminino $(37,14 \%$ e $18,62 \%$, respectivamente), sugerindo que grande parte das mulheres migra acompanhada dos seus parceiros ou estabelece uma união matrimonial após a imigração. Como sublinha Bakewell (2009), os migrantes muitas vezes sustentam vínculos transnacionais, e a migração internacional de casamento está crescendo à medida que os migrantes olham para seu local de origem para encontrar parceiros, que posteriormente migram para se juntarem ao cônjuge. Por sua vez, Tolentino (2009) afirma que a feminização dos fluxos migratórios é reflexo do maior acesso da mulher à educação, da sua maior participação nas atividades econômicas fora do agregado familiar, assim como do aumento do tráfico de mulheres - embora este seja um fator de difícil quantificação dada a natureza criminal desta prática.

A crise interna do Zimbabawe também incentivou a maior mobilidade de trabalhadoras do sexo deste país para as províncias do centro de Moçambique, dentre elas Tete. Além do mercado sexual, existe um elevado comércio interfronteiriço direto entre as províncias de Tete e Malawi e Zimbabwe, assim como entre Manica e Zimbabwe. Este tipo de comércio é cada vez mais praticado por mulheres que compram e revendem produtos diversos ao longo das fronteiras internacionais (RAIMUNDO, 2011c). Por outro lado, como será ilustrado pelos resultados da pesquisa qualitativa, Tete tornou-se também um importante mercado de trabalho para as mulheres em serviços domésticos, restaurantes e casas particulares, principalmente na Vila de Luenha e em Cuchamano.

\section{Registros de trabalhadores zimbabweanos}

Dados da Direção Provincial do Trabalho, Emprego e Segurança Social, responsável pelos registros de trabalhadores estrangeiros a nível provincial, revelam que, entre 2007 e junho de 2017, havia um total de 428 trabalhadores zimbabweanos (412 homens e 16 mulheres) na província de Tete, distribuídos entre 92 empresas e/ou instituições. Tal como referimos anteriormente, julgamos que esses dados são subestimados. De toda forma, as informações mostram claramente que a mão de obra zimbabweana nas empresas de vários setores em Tete, com destaque para mineradoras, é composta majoritariamente por homens (96,30\%). Se o mercado de trabalho nas empresas mineradoras é excludente para os que não têm qualificações acadêmicas e experiência específica nesta área de trabalho, ele é muito mais rígido para as mulheres que, na sua maioria, têm nível de escolaridade mais baixo do que os homens, como sugerido pelos resultados do Censo. Por outro lado, a própria natureza dos trabalhos nas minas exige habilidades físicas que, para muitos empregadores, as mulheres supostamente não possuem. Isto em um contexto em que a 
desigualdade de gênero ainda é uma realidade, com uma cultura local em que as mulheres tendem a ser relegadas aos trabalhos domésticos.

Em suma, diversos fatores concorrem para essa diferença abismal entre o número de trabalhadores formais zimbabweanos do sexo masculino e do feminino. De um lado, os trabalhos ofertados pelos megaprojetos da mineração em Tete requerem formação técnico profissional ou experiência em certas áreas específicas, que as mulheres geralmente não possuem (conforme descrito nos resultados do Censo). De outro lado, apesar de as mulheres constituírem a maioria da população de imigrantes zimbabweanos em Tete e da sua crescente participação nas atividades econômicas fora do agregado familiar na África Austral (TOLENTINO, 2009), elas estão sobrerrepresentadas no setor informal da economia, particularmente em serviços domésticos e no comércio informal transfronteiriço (RAIMUNDO, 2011a).

\section{Entrevistas com imigrantes zimbabweanos}

Foram realizadas 40 entrevistas semiestruturadas com imigrantes procedentes do Zimbabwe, residentes em Tete, sendo 16 mulheres (40\%) e 24 homens (60\%). As entrevistas contemplam indivíduos entre 19 e 72 anos, sendo que a média de idade da população amostral foi de 36,6 anos. Os grupos etários com mais entrevistados foram os de 30 a 39 anos (37,5\%) e de 19 a 29 anos (30\%), com grande parte dos entrevistados casados ou vivendo maritalmente $(67,5 \%)$. Destaca-se que seis entrevistados (15\%) afirmaram não ter estudado ou não ter concluído o ensino primário, dez (25\%) possuem o ensino primário completo, 20 (50\%) têm o ensino secundário completo e quatro (10\%) concluíram o ensino superior. Em relação ao setor de trabalho, 13 participantes declararam trabalhar no setor formal $(32,5 \%)$ e outros 27 $(67,5 \%)$ no setor informal. Neste último estavam metade dos homens e $93,7 \%$ das mulheres. Estas características sociodemográficas dos entrevistados seguem as tendências encontradas para a população imigrante no Censo e no Registro de Trabalhadores.

A Tabela 1 mostra os principais resultados das entrevistas realizadas com imigrantes zimbabweanos em Tete. Uma das observações mais relevantes das entrevistas refere-se ao processo de mobilidade descendente experimentado pelos migrantes no mercado laboral: enquanto $70 \%$ declararam trabalhar no mercado formal e $30 \%$ no setor informal da economia no seu país de origem, esta proporção se inverte no país de destino.

Esse dado sugere que alguns dos imigrantes qualificados conseguem emprego nas empresas mineradoras e outros setores formais, enquanto a maioria com baixa qualificação e pouca experiência profissional disputa as atividades informais (venda ambulante, prostituição, venda de drogas) com os nativos (MOSCA; SELEMANE, 2010).

Nem todos aqueles que tinham um emprego formal no Zimbabwe são qualificados, sendo, em sua maioria, trabalhadores nas plantações de tabaco, milho, cana de açúcar, dos fazendeiros brancos, onde faziam trabalhos que muitas vezes não exigiam qualificações acadêmicas. Há casos de pessoas que não sabem ler e escrever, mas tinham um emprego formal no Zimbabwe. 
É importante pontuar que os trabalhos ofertados pelos megaprojetos da mineração em Tete requerem alguma formação técnico profissional ou experiência em certas áreas específicas.

TABELA 1

Principais resultados das entrevistas com imigrantes

Província de Tete - 2017

\begin{tabular}{|c|c|c|c|c|c|c|}
\hline \multirow{2}{*}{ Questões/temas } & \multicolumn{2}{|c|}{ Total } & \multicolumn{2}{|c|}{ Homens } & \multicolumn{2}{|c|}{ Mulheres } \\
\hline & $\mathbf{N}$ & $\%$ & $\mathrm{~N}$ & $\%$ & $\mathrm{~N}$ & $\%$ \\
\hline \multicolumn{7}{|l|}{ Setor de trabalho na origem (Zimbabwe) } \\
\hline Setor formal & 28 & 70,00 & 20 & 83,30 & 8 & 50,00 \\
\hline Setor informal & 12 & 30,00 & 4 & 16,70 & 8 & 50,00 \\
\hline \multicolumn{7}{|l|}{ Setor de trabalho no destino (Moçambique) } \\
\hline Setor formal & 13 & 32,50 & 12 & 50,00 & 1 & 6,25 \\
\hline Setor informal & 27 & 67,50 & 12 & 50,00 & 14 & 93,75 \\
\hline \multicolumn{7}{|l|}{ Motivos de migração } \\
\hline Econômicos & 18 & 45,00 & 12 & 50,00 & 6 & 38,00 \\
\hline Políticos & 20 & 50,00 & 10 & 42,00 & 10 & 63,00 \\
\hline Espirituais & 2 & 5,00 & 2 & 8,00 & 0 & 0,00 \\
\hline \multicolumn{7}{|l|}{ Porque a escolha de Tete como destino } \\
\hline Ligações ancestrais e de parentesco & 22 & 55,00 & 12 & 50,00 & 10 & 63,00 \\
\hline Proximidade geográfica & 4 & 10,00 & 3 & 13,00 & 1 & 6,25 \\
\hline Oportunidade de emprego (megaprojetos) & 2 & 5,00 & 1 & 4,17 & 1 & 6,25 \\
\hline Todas as três opções & 12 & 30,00 & 8 & 33,33 & 4 & 25,00 \\
\hline \multicolumn{7}{|l|}{ Se sofreu algum tipo de preconceito étnico/tribal ou xenofobia } \\
\hline Não sofreu nenhuma violência ou preconceito & 28 & 70,00 & 18 & 75,00 & 10 & 62,50 \\
\hline Sofreu violência verbal & 12 & 30,00 & 6 & 25,00 & 6 & 37,50 \\
\hline \multicolumn{7}{|l|}{ Envio de ajuda financeira na origem (Zimbabwe) } \\
\hline Envia ajuda financeira & 20 & 50,00 & 14 & 58,33 & 6 & 37,50 \\
\hline Não envia ajuda financeira & 20 & 50,00 & 10 & 41,67 & 10 & 62,50 \\
\hline \multicolumn{7}{|l|}{ Se pretende retornar ao Zimbabwe } \\
\hline Não pretende retornar & 28 & 70,00 & 17 & 70,83 & 11 & 68,75 \\
\hline Pretende retornar se as coisas melhorarem no Zimbabwe & 12 & 30,00 & 7 & 29,17 & 5 & 31,25 \\
\hline
\end{tabular}

Fonte: Pesquisa de campo, janeiro e fevereiro 2017.

Outro resultado relevante das entrevistas refere-se à forma como os imigrantes zimbabweanos fizeram o ranking das questões mais importantes que motivaram a decisão de migrar. Para $95 \%$ dos entrevistados, os problemas de caráter econômico e político ${ }^{9}$ aparecem como as principais causas para deixar o país. Os entrevistados comentaram que a polêmica reforma da terra implementada pelo governo de Roberto Mugabe, a partir de 2000, que expulsou milhares de fazendeiros brancos do país, mergulhou o Zimbabwe numa crise sociopolítica e econômica sem precedentes que dura até hoje. Milhares de trabalhadores ficaram sem emprego quando as fazendas deixaram de produzir, pois

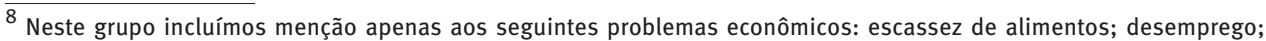
hiperinflação com crescimento negativo; contração da produção industrial e agrícola.

${ }^{9}$ No grupo de problemas de caráter político, incluímos menção a: perseguições; violência física; destruição de residências; e até mesmo morte por motivações político-partidárias aos membros ou suspeitos de serem membros dos partidos da oposição.
} 
estima-se que os fazendeiros brancos então expulsos empregavam cerca de $90 \%$ da população (BRANCO, 2008).

Outras fontes-chave de rendimento no Zimbabwe, como a indústria de mineração do ouro e do turismo, também se ressentiram fortemente, piorando ainda mais a já precária situação do desemprego. Além disso, a falta de divisas devido à repentina diminuição das exportações agrícolas implicou a escassez de meios para fazer face à carência alimentar e ao pagamento da energia comprada na África do Sul e em Moçambique. Houve, ainda, falha de serviços essenciais, como o fornecimento de água nas principais cidades e o não funcionamento do sistema de saúde devido à falta de medicamentos e de pessoal qualificado nos hospitais. Todos esses problemas, somados à estratosférica taxa de inflação do país - 2.200.000\% em julho de 2008 - obrigaram milhares de zimbabweanos a abandonarem o país, principalmente em direção à vizinha África do Sul (BRANCO, 2008). Alguns discursos dos nossos entrevistados, como os apresentados a seguir, reforçam a importância desses fatores contextuais que favoreceram a expulsão populacional a partir do Zimbabwe.

Eu saí do Zimbabwe por causa de dificuldades econômicas. De um tempo para cá as empresas, as minas fecharam no Zimbabwe, e há agora falta de emprego e muitos jovens tal como eu estão a sair do Zimbabwe para outros países porque a situação econômica não está boa. (Entrevista \#1, sexo masculino, 32 anos de idade; ano de chegada 2006)

Sou formado pela universidade em marketing, e ganhava bom salário no Zimbabwe, mas quando a inflação veio estragou tudo. Tínhamos dinheiro, mas o nosso dinheiro não tinha valor, você podia ter maços e maços de dinheiro, mas não conseguia comprar as coisas mais básicas para sobreviver; os preços dos produtos alimentícios e outros aumentavam a cada dia, e nós simplesmente não aguentamos e foi mesmo por essa razão que decidi mudar-me para Moçambique. (Entrevista \#13, sexo masculino, 41 anos de idade, ano de chegada 2005)

0 contexto político no Zimbabwe representou uma dimensão importante na determinação dos fluxos imigratórios para Tete. Os problemas criados pela crise da reforma agrária, agravada pelas sanções econômicas impostas ao país pelo Reino Unido e pelos países ocidentais, fizeram com que a maioria da população olhasse para o partido da oposição, então recém-criado, como uma alternativa. Prova disso foi o número crescente de votantes da oposição nos vários pleitos eleitorais manchados por irregularidades diversas, e a consequente perseguição pelo governo. Em março de 2007, centenas de membros da oposição e da sociedade civil foram presos, incluindo o próprio presidente do maior partido da oposição no Zimbabwe, Movement For Democratic Change (MDC), Morgan Tsvanguirai.

Mesmo assim, o partido da oposição chegou a ganhar as eleições Legislativas de 2008 e o primeiro turno das eleições presidenciais, com Tsvanguirai obtendo 47,8\% dos votos contra 43,3\% de Roberto Mugabe. Prevendo a vitória de Tsvanguirai na segunda volta das eleições, o governo de Mugabe incrementou ainda mais as suas táticas de coerção e persuasão, de estilo militar, acionando a chamada “Operação Makavhoterapapi”, ${ }^{10}$ em que

\footnotetext{
$\overline{10}$ Outras operações do gênero foram acionadas para o setor privado e a economia, a reforma agrária, o comércio informal ou habitação, a "Operação Murambatsvina”, "Operação Dzikisa Mitengo" ou a "Operação Taguta”.
} 
fez uso de sequestros, espancamentos e destruição de propriedades privadas como forma de obrigar eventuais eleitores de Tsvangirai a não votarem no candidato. Esta operação ocasionou a morte de cerca de cem pessoas, além de deixar três mil feridas e originar um número não estimado de deslocados internos e refugiados (HUMAN RIGHTS WATCH, 2008; BRANCO, 2008; ZAGO, 2009).

Na narrativa de diversos entrevistados, notam-se indícios de como a violência político-partidário levada a cabo pelo governo, como forma de intimidação, motivou as decisões de migração para Tete:

O problema político, principalmente a violência eleitoral, foi determinante para eu sair imediatamente do Zimbabwe. A minha casa e todos meus bens foram queimados por questões políticas, fui acusado de ser da oposição, e para escapar da morte tive que fugir dessa perseguição. (Entrevista \#8, sexo masculino, 42 anos de idade, ano de chegada 2008)

Primeiro o dinheiro é que começou a não ser fácil de apanhar para sustentar a família. Mas eu particularmente tomei a decisão de sair do Zimbabwe devido à violência eleitoral. Em tempos de campanha eleitoral, havia sempre agressões uns contra os outros com acusações de ser deste ou daquele partido. Todos agrediam a todos, já não sabíamos quem estava a proteger o povo ou quem estava contra ele. Havia lutas em todos os lados $e$ às vezes éramos obrigados a dormir no mato como se fosse tempo de guerra. Não estávamos em paz lá por isso decidi mesmo sair com a minha esposa, porque nosso povoado fica bem perto daqui do outro lado da fronteira. (Entrevista \#24, sexo masculino, 66 anos de idade, ano de chegada 2008)

Outra informação relevante obtida a partir das entrevistas refere-se à escolha da província moçambicana de Tete como destino desses imigrantes. É comum ouvir nos canais de informações, como televisão, rádio, jornais e até mesmo em alguns artigos científicos, que foram os megaprojetos de mineração recentemente instalados em Tete que atraíram a entrada massiva dos zimbabweanos. Como demonstrado, a migração dos zimbabweanos já se fazia sentir antes da instalação dos megaprojetos em 2007, na medida em que ela foi impulsionada pela crise interna do Zimbabwe que começou em 2000. Por isso, antes de 2007, a explicação encontra-se mais pelas afinidades sociais e culturais e pela proximidade geográfica das regiões de origem (Zimbabwe) e de destino (Tete). A avaliação das entrevistas permitiu inferir que $65 \%$ dos entrevistados afirmaram ter escolhido Tete como destino por conta das ligações ancestrais e de parentesco e pela proximidade geográfica, como refletem os trechos a seguir.

Quando as coisas ficaram difíceis no Zimbabwe, eu apenas atravessei a fronteira, para este lado de Moçambique, porque a minha localidade onde nasci e vivia lá no Zimbabwe é bem próxima, olha que, tanto o lado moçambicano como o lado zimbabweano aqui na fronteira pertence à mesma etnia e ao mesmo regulado. Essa terra é dos malembe, é da etnia Malembe e de tempo em tempo, mesmo antes de me mudar em definitivo para aqui, nós já cruzávamos a fronteira para cerimônias várias, como Bona, falecimentos, Kamutimuti. (Entrevista \#34, sexo masculino, 38 anos de idade, ano de chegada 2005) 
Eu nasci no Zimbabwe, porém os meus pais são daqui de Moçambique, saíram daqui fugindo da guerra há muito tempo. Por isso que eu e alguns dos meus irmãos viemos aqui ao encontro da família dos meus pais, uma vez que tanto meu pai como minha mãe faleceram no Zimbabwe antes da gente se mudar para cá. Mas conseguimos encontrar a família. (Entrevista \#21, sexo feminino, 32 de idade, ano de chegada 2010).

Estas ligações transnacionais (CASTLES, 2005) são cruciais para sustentar a vida social e econômica, tanto dos que emigraram quanto dos que permaneceram no país de origem. De fato, os laços culturais e linguísticos desempenham papel importante, particularmente para os imigrantes de baixa qualificação. Por exemplo, os imigrantes zimbabweanos, que têm quase na totalidade o shona como seu idioma principal, estão na sua maioria no sul da província de Tete, onde as línguas dos nativos são subgrupos da língua shona, facilitando, assim, o processo de integração. Tal como sublinham Jalal et al. (2010), esses laços vão além da linguagem e envolvem outros aspectos sociais e culturais: a religião, a alimentação, os hábitos de trabalho e os costumes familiares.

A análise da escala temporal de chegada dos zimbabweanos entrevistados em Tete indica que $37,5 \%$ chegaram antes ou durante o ano de 2007 (dados não apresentados). Com a implantação das multinacionais do setor de mineração a partir de 2007, quando a brasileira Vale começou a explorar o carvão, e com a chegada de tantas outras empresas mais tarde, o fluxo migratório dos zimbabweanos se intensificou, ao mesmo tempo que começou um novo fluxo de imigrantes de outras províncias moçambicanas e estrangeiros de países diversos. Alguns entrevistados falaram das oportunidades de emprego nas recém-instaladas empresas mineradoras do carvão mineral em Tete, como pode se ver nos trechos a seguir.

Há muitos zimbabweanos que estão a sair de lá para cá porque a situação está mal no Zimbabwe. Moçambique hoje está melhor que o Zimbabwe, por isso muitos estamos a mudar para Moçambique. $O$ crescimento econômico de Tete está a ser falado em todo lado. Toda gente tem olhos e ouvidos abertos para acompanhar notícias de Tete. Toda gente sabe que em Tete alguma coisa está acontecer. (Entrevista \#10, sexo masculino, 40 anos de idade, ano de chegada 2006)

Vim a Tete porque aqui tem oportunidade de emprego e vive-se melhor do que lá do outro lado [da fronteira]. (Entrevista \#37, sexo feminino, 38 anos de idade, ano de chegada 2010).

Também perguntamos aos entrevistados sobre o envio de apoio financeiro para seus familiares no país de origem, não só pela importância das remessas, mas também porque essa questão é relevante para a discussão sobre probabilidade de retorno e de identidades transnacionais. Nesse sentido, $50 \%$ dos entrevistados informaram que enviam dinheiro para Zimbabwe e os outros $50 \%$ não enviam. Porém, quando estratificamos as remessas por sexo, observa-se que $58,33 \%$ dos homens ajudavam as famílias na origem, enquanto entre as mulheres esse percentual corresponde a $37,50 \%$. Esses resultados, mais uma vez, são influenciados pelo mercado de trabalho, dado que a maioria dos homens possui emprego formal - nas mineradoras -, por conseguinte ganham relativamente melhor que aqueles que estão no mercado informal. Considerando que a maioria das mulheres no destino não 
tem emprego formal, seu poder financeiro também é limitado, o que explicaria sua menor propensão a enviar remessas. Algumas entrevistadas confirmaram esta hipótese.

[...] não mando nada, porque não tenho o que mandar, uma vez que sou dependente do tio, que vive comigo. Por acaso gostaria de apoiar minha avó que ficou com os meus irmãos mais novos no Zimbabwe. (Entrevista \#2, sexo feminino, 19 anos idade, ano de chegada 2012)

[...] desde que estou aqui nunca me comuniquei com a minha família, mas também o pouco que ganho é só para eu aguentar, não dá para enviar. (Entrevista \#39, sexo feminino, 24 anos de idade, ano de chegada 2015)

Embora os fluxos de remessas sejam muitas vezes vistos como um fator importante na redução da pobreza, facilitando o investimento das famílias e estimulando o crescimento econômico e, a nível macroeconômico, melhorando a balança de pagamentos dos países beneficiários, em muitos países da África, nos níveis micro e meso, as remessas são apenas um salário de sobrevivência, sendo a sua contribuição para o desenvolvimento econômico [neoclássico] pouco significativa (BILSBORROW, 2016).

Como já indicado, nos últimos tempos têm sido frequentes as ondas de violências xenofóbicas em alguns países que historicamente acolheram os imigrantes da região, nomeadamente a África do Sul e o Botsuana. Por esta razão, perguntamos aos entrevistados se sofreram algum tipo de preconceito étnico/tribal ou xenofobia: $70 \%$ afirmaram não ter sofrido nenhum tipo de preconceito ou violência xenofóbica e 30\% mencionaram ter sofrido alguma violência verbal, mas que não passou disso. Apesar dos relatos de situações desagradáveis, não houve registros de violência extrema, torturas físicas e assassinatos de estrangeiros, como é reportado com alguma frequência no território sul-africano (BRANCO, 2008).

Aqui em Tete os estrangeiros não são discriminados nem sofrem atos de xenofobia como costuma se fazer na África do Sul; aqui os estrangeiros vivem à vontade, a meu ver não são tão discriminados como acontece em outros países. (Entrevista \#34, sexo masculino, 38 anos de idade, ano de chegada 2007).

Aqui sofremos discriminação, não somos livres! Somos chamados Anyakubwera (vindouro) e somos privados de muitas coisas. Mesmo no momento das entrevistas para emprego, quando descobrem que somos estrangeiros às vezes não somos admitidos, somos exigidos muitos documentos que não conseguimos tratar. Mas aqui é melhor que na África do Sul onde há xenofobia de verdade, porque aí os estrangeiros são batidos e até mortos, já aqui somos apenas insultados. (Entrevista \#6, sexo masculino, 25 anos de idade, ano de chegada 2008).

Já fui insultada muitas vezes, somos chamadas de putas principalmente pelas mulheres daqui. Dizem que saímos do Zimbabwe para vir fazer prostituição por aqui, e que estamos a roubar maridos delas. As mulheres não gostam nada da gente. Mas não posso mentir que me bateram como aquilo que acontece na África do Sul; aqui somos insultadas. (Entrevista \#40, sexo feminino, 36 anos de idade, ano de chegada 2009).

As entrevistas evidenciam que casos isolados de discriminação e violência verbal contra os imigrantes zimbabweanos também acontecem em Tete, mas não comparáveis 
ao que costuma se assistir na África do Sul, onde grupos de pessoas promovem ondas de violência em cidades grandes como Durban e Johanesburgo, por exemplo. Portanto, argumenta-se que esta percepção de Moçambique, e Tete em particular, como um lugar comparativamente mais tolerante e aberto à imigração pode estar influenciando a escolha dos zimbabweanos por estes destinos.

Finalmente, sobre a intenção de retornar ao seu país de origem, apesar do Zimbabwe ainda estar mergulhado numa crise generalizada, $70 \%$ dos entrevistados disseram que pretendiam morar definitivamente em Tete e que não pensavam em retornar ao seu país e apenas $30 \%$ afirmaram que retornariam caso as coisas um dia melhorassem na sua terra natal. Talvez a esperança dos imigrantes de retornar ao Zimbabwe tenha-se reacendido como consequência dos recentes acontecimentos políticos no país, nomeadamente o golpe de Estado efetuado pelos militares, que pôs fim ao longo reinado do presidente Mugabe após 37 anos no poder, e a consequente ascensão à Presidência de Emersom Mnangagwa em novembro de 2017.

\section{Conclusões}

Este artigo buscou contribuir para o entendimento da dinâmica das migrações internacionais sul-sul, a partir do estudo de caso da recente imigração de zimbabweanos para a província de Tete, Moçambique, por meio do cruzamento de técnicas de análises quantitativas e qualitativas.

Os resultados mostram que a maioria dos imigrantes zimbabweanos em Tete está inserida no setor informal da economia e seus locais de trabalho não constam nos registros oficiais do Estado. 0 recurso a estratégias informais de sobrevivência se faz necessário, uma vez que grande parte desses imigrantes possui baixo nível de escolaridade, tal como mostraram os resultados do Censo. 0 mercado de trabalho formal de Tete é composto, principalmente, por empresas mineradoras e subcontratadas, o que impõe uma série de pré-requisitos para contratação de mão de obra, como um alto nível de escolaridade ou experiência em áreas específicas. Os mecanismos de seletividade dos megaprojetos de Tete são discriminatórios para a mão de obra não qualificada e, portanto, para a maioria dos imigrantes zimbabweanos, embora as entrevistas mostraram que a maior parte destes trabalhava no setor formal no seu país de origem.

Embora o atrativo econômico seja uma das principais motivações da migração, os resultados indicam que a escolha de Tete como destino por parte dos zimbabweanos não se resume ao mercado de trabalho, mas é explicada também pela proximidade geográfica e fatores sociais relacionados a ligações ancestrais e de parentesco e afinidades culturais entre os dois povos. Além disso, a crise sociopolítica interna do Zimbabwe aparece como um dos principais fatores motivadores da emigração da população daquele país.

Argumentamos que a questão política se soma a dois fatores importantes para tornar Tete, historicamente, uma região de emigração, bem como uma região de acolhimento 
de imigrantes: a longa tradição da mobilidade intrarregional na África Austral, facilitada por fronteiras relativamente porosas e fortes laços culturais, linguísticos e de parentesco entre estes países; e o aparente crescimento econômico da província de Tete, anunciado pela instalação dos megaprojetos de mineração em um momento em que a África do Sul (principal receptor de imigrantes na região) assistia a ondas de xenofobia, com centenas de estrangeiros sofrendo algum tipo de violência.

Assim, as evidências discutidas neste artigo contribuem para um melhor entendimento da dinâmica das migrações sul-sul, uma área de estudos relativamente ofuscada pelo viés da literatura nas trajetórias e dinâmicas das migrações sul-norte, apesar da sua crescente importância nos fluxos migratórios globais.

Neste contexto, indica-se que Tete e Moçambique necessitam criar estratégias frente à questão migratória, como, por exemplo, preparar políticas públicas de gestão dos fluxos migratórios para que estes atuem em prol do desenvolvimento do país e dos imigrantes e suas famílias. Além disso, faz-se necessário discutir o fenômeno da migração em Moçambique no âmbito mais amplo de desenvolvimento regional da Comunidade de Desenvolvimento da África Austral (SADC). Mesmo assim, uma dimensão importante a ser considerada em maior profundidade em estudos futuros sobre a migração sul-sul na África Austral é a dimensão de gênero, dado que, tanto em Tete como no continente africano, as mulheres vêm ganhando espaço nos fluxos migratórios, em consonância com a tendência mundial de feminização das migrações (DONATO; GABACCIA, 2016; GIORGULI; ANGOA, 2016). Nesse sentido, estudos futuros poderiam explorar questões relacionadas às particularidades dos laços e práticas socioeconômicas transnacionais mantidas pelas mulheres, as múltiplas transformações que estas produzem e os impactos da migração na (re)construção das identidades étnicas, de classe e de gênero das mulheres migrantes, dentre outros.

A crise interna zimbabweana não é apenas mais um episódio que incide sobre um Estado vizinho, já que o Zimbabwe ocupa um histórico lugar de destaque no sistema econômico e político da região. Dada a exiguidade de estudos que abordam a migração para Moçambique, e Tete em particular, este artigo procurou refletir sobre o movimento migratório intrarregional no contexto da África Austral, numa altura em que os destinos se multiplicam e as trajetórias tradicionais são contrariadas, tornando a compreensão do fenômeno migratório cada vez mais complexa.

\section{Referências}

AFDB.ORG. Africa and the BRICS: a win-win partnership? African Development Bank Group. 2013. Disponivel em: https://blogs.afdb.org/fr/afdb-championing-inclusive-growth-across-africa/post/ africa-and-the-brics-a-win-win-partnership-12098. Acesso em: 20 jul. 2021.

BAENINGER, R.; BÓGUS, L. C. M.; MOREIRA, J. L. B.; VEDOVATO, L. S. R.; FERNANDES, D.; SOUZA, M. R. D.; BALTAR, C. U. S.; PERES, R. G. E.; WALDMAN, T. C.; MAGALHÃES, L. S. F. A. Migrações sul-sul. Campinas: Núcleo de Estudos de População “Elza Berquó” (Nepo), Universidade Estadual de Campinas (Unicamp), 2018. 
BAKEWELL, O. South-south migration and human development: reflections on African experiences. United Nations Development Programme, 2009. (Human Development Research Paper, 2009/07).

BETTS, A. Survival migration: failed governance and the crisis of displacement. Ithaca and London: Cornell University Press, 2013.

BILSBORROW, R. Concepts, definitions and data collection approaches. In: WHITE, M. International handbook of migration and population distribution. New York: Springer, 2016. p. 109-156.

BRANCO, L. C. África e a crise no Zimbabwe. Lusíada - Política Internacional e Segurança, n. 1, p. 41-66, 2008.

CASTLES, S. Globalização, transnacionalismo e novos fluxos migratórios. Dos trabalhadores convidados às migrações globais. Trad. Frederico Ágoas. Lisboa: Fim de Século, 2005.

CASTLES, S. Understanding global migration: a social transformation perspective. Journal of Ethnic and Migration Studies, v. 36, p. 1565-1586, 2010.

CEBOLA, T. P. 0 impacto da Declaração Unilateral da Independência para a economia política da Rodésia e da região, 1965-1980. Monografia de Licenciatura (História) - Faculdade de Letras e Ciências Sociais, Universidade Eduardo Mondlane (UEM), Maputo, 2010.

COLEMAN, D. Immigration and ethnic change in low-fertility countries: a third demographic transition. Population and Development Review, v. 32, p. 401-446, 2006. DOI:10.1111/j.17284457.2006.00131.x.

CRESWELL, J. W. Projeto de pesquisa: métodos qualitativos, quantitativos e mistos. Sage, 2010.

DAS NEVES, J. Tete e o trabalho migratório para a Rodésia do Sul, 1890-1913. Arquivo - Boletim do Arquivo Histórico de Moçambique, n. 10, p. 83-103, 1991.

DODSON, B. et al. Gender, migration and remittances in Southern Africa. Waterloo, ON: Southern African Migration Project, 2008. (SAMP Migration Policy Series, n. 49).

DONATO, K.; GABACCIA, D. The global feminization of migration: past, present, and future. Migration Information Source, Jun. 2016.

FAZITO, D. The role of social networks in human migration. Revista Interdisciplinar da Mobilidade Humana (REMHU), n. 17, p. 5-23, 2009.

GAGNON, J.; KHOUDOUR-CASTÉRAS, D. South-south migration in west Africa: addressing the challenge of immigrant integration. OECD Development Centre, 2012 (Working Paper, n. 312).

GARCIA, A. BRICS investment agreements in Africa: more of the same? Studies in Political Economy. A Socialist Review, v. 98, n. 1, p. 24-47, 2017.

GEIGER, M.; PÉCOUD, A. Migration, development and the 'migration and development nexus'. Population, Space and Place, v. 19, p. 369-374, 2013.

GIORGULI, S. E.; ANGOA, M. A. International migration, gender and family: a miroir from Latin America. In: WHITE, M. International handbook of migration and population distribution. New York: Springer, 2016. p. 543-572.

GLASER, B. G.; STRAUSS, A. L. The discovery of grounded theory: strategies for qualitative research. Chicago: Aldine, 1967.

GUILLON, M. La mosaïque des migrations africaines. Esprit, n. 8-9, août-septembre 2005.

HUGO, G. Environmental concerns and international migration. International Migration Review, v. 30, Special Issue: Ethics, Migration, and Global Stewardship, 1996. 
HUMAN RIGHTSWATCH. Bullets for each of you: State-sponsored violence since Zimbabwe's March 29 elections. June 2008. Disponivel em: http://www.hrw.org/reports/2008/zimbabwe0608/ index.htm. Acesso em: 15 nov. 2017.

INSTITUTO NACIONAL DE ESTATÍSTICA. Resultados definitivos do Censo 2007. INE, 2007.

IOM - International Organization for Migration. World migration report 2018. Geneva, 2017.

JALAL, O. et al. Mode de vie, habitudes alimentaires et identité des immigrants sénégalais au Maroc. In: AFRICAN MIGRATION WORKSHOP. Proceedings [...]. Dakar, November 2010.

JORGENSEN, N. V. et al. International migration and household living arrangements among transnational families in Brazil. Journal of Ethnic and Migration Studies, p. 1-19, 2019.

LUMMUMBA-KASONGO, T. China-Africa relations: a neo-imperialism or a neo-colonialism? A reflection. African and Asian Studies, v. 10, n. 2-3, p. 234-266, 2011.

MACKINTOSH, M. O capital privado e o Estado no sistema de transportes da África Austral. Estudos Moçambicanos, n. 5/6, p. 83-128, 1986.

MARQUES, J. C. L. Os portugueses na Suiça: migrantes europeus. Lisboa: Imprensa de Ciências Sociais, 2008.

MINTER, W.; SCHMIDT, E. When sanctions worked; the case of Rhodesia reexamined. African Affairs, v. 87, n. 347, p 207- 237, 1980.

MLAMBO, A. S. Prelude to the 1979 Lancaster House Constitutional Conference on Rhodesia: the role of international economic sanctions reconsidered. Historia, v. 50, n. 1, p. 147-172, May 2005.

MOSCA, J.; SELEMANE, T. El Dourado Tete: os mega projectos de mineração. Maputo: CIP, 2011.

MOSCA, J.; SELEMANE, T. Mega projectos no meio rural, desenvolvimento do território e pobreza: o caso de Tete. Maputo: CIP, 2012.

MUANAMOHA, R. Padrões da migração laboral indocumentada de Moçambique para a África do Sul. CAP/UEM, 2011.

MUANAMOHA, R.; RAIMUNDO, I. M. A dinâmica migratória em Moçambique. In: ARNALDO, C.; CAU, B. M. (org.). Dinâmicas da população e saúde em Moçambique. Maputo: Cepsa, 2013.

OKOLO, A.; AKWU, J. China's foreign direct investment in Africa's land: hallmarks of neocolonialism or South-South cooperation? African Review, v. 8, n. 1, p. 44-59, 2016.

ONU. Migração mundial em números: uma contribuição conjunta do UNDESA e da OCDE para o diálogo de alto nível das Nações Unidas sobre migração e desenvolvimento. OECD-UNDESA, Out. 2013.

PATRÍCIO, G. Moçambique: compulsando as migrações internas e internacionais. InterEspaço. Revista de Geografia e Interdisciplinaridade, v. 2, n. 5, p. 78-101, jan./abr. 2016.

PATRÍCIO, M. Identidade étnica, regional ou transnacional? O caso Ndau. In: XI CONGRESSO LUSO-AFRO-BRASILEIRO DE CIÊNCIAS SOCIAIS. Anais [...]. Salvador, BA: Centro de Estudos Afro-Orientais (CEAO), Universidade Federal da Bahia, 2011.

PEIXOTO, J. As teorias explicativas das migrações: teorias micro e macro-sociológicas. Lisboa: Instituto Superior de Economia e Gestão, 2004. (Socius Working Papers, n. 11/2004).

PENDLETON, W. et al. Migration, remittances and development in Southern Africa. Cape Town: Southern African Migration Project, 2006. (Migration Policy Paper Series, v. 44). 
RAIMUNDO, I. M. Causas, consequências e padrões da migração internacional de Moçambique: questões emergentes no espaço da lusofonia. Revista Internacional de Língua Portuguesa, III série, n. 24, 2011a.

RAIMUNDO, I. M. Migrações em Moçambique: reflexões sobre uma política de migração. Revista Estudos Moçambicanos, n. 22, 2011 b.

RAIMUNDO, I. M. Migração e HIV/SIDA em Moçambique: desafios da região centro de Moçambique. GEOUSP - Espaço e Tempo, São Paulo, n. 29, especial, p. 43-55, 2011c.

RATHA, D.; SHAW, W. South-South migration and remittances. Washington D.C.: Development Prospects Group, World Bank, 2007. (World Bank Working Paper, n. 102).

RICH, T.; RECKER, S. Understanding Sino-African relations: neocolonialism or a new era? Journal of International and Area Studies, v. 20, n. 1, p. 61-76, 2013.

ROBERTS, A. A history of Zambia. London: Heinemann, 1976/1981.

SKELDON, R. Interlinkages between internal and international migration and development in the Asian region. Population, Space and Place, v. 12, n. 1, p. 15-30, 2006.

TOLENTINO, N. C. Migrações, remessas e desenvolvimento: o caso africano. Lisboa: Socius, 2009. (Socius Working Paper, n. 09).

UA - União Africana. Reunião de peritos sobre a migração e desenvolvimento. Argel, 3-5 de abril 2006.

UN-DESA - United Nations, Department of Economic and Social Affairs, Population Division. International migrant stock 2019. United Nations database, POP/DB/MIG/Stock/Rev.2019. New York: United Nations, 2019.

UNDP - United Nations Development Programme. World population prospects: 2019 revision. New York: United Nations Population Division, 2019. Disponível em: https://population.un.org/ wpp/.

UNHCR - United Nations High Commissioner for Refugees. Global trends: forced displacement in 2018. Geneva: UNHCR, 2019.

ZAGO, E. F. A crise zimbabuana sob as lentes da justiça internacional. Cadernos de Relações Internacionais, v. 2, n. 1, 2009.

ZAPATA, G. P.; GUEDES, G. R. Population mobilities in the twenty-first century: trends, conflicts, and policies N-IUSSP [Online]. International Union for the Scientific Study of Population (IUSSP), 2019.

ZHOU, J.; HE, W. Chinese cooperation in Mozambique and Angola: a focus on agriculture and health. Rio de Janeiro: PUC, BRICS Policy Center, 2014. (BPC Papers, v. 2, n. 3).

\section{Sobre os autores}

Tomás Cebola é mestre em Demografia pelo Departamento de Demografia e Centro de Desenvolvimento e Planejamento Regional (Cedeplar) da Universidade Federal de Minas Gerais (Brasil). Técnico superior de Demografia no Instituto Nacional de Estatística (INE), na Delegação de Tete, Moçambique. 
Alisson Barbieri é PhD em City and Regional Planning, University of North Carolina at Chapel Hill (EUA). Professor associado do Departamento de Demografia e pesquisador do Centro de Desenvolvimento e Planejamento Regional (Cedeplar), ambos da Universidade Federal de Minas Gerais (UFMG).

Gisela Zapata é PhD em Human Geography, Newcastle University (Reino Unido). Professora adjunta do Departamento de Demografia e pesquisadora do Centro de Desenvolvimento e Planejamento Regional (Cedeplar), ambos da Universidade Federal de Minas Gerais (UFMG).

\title{
Endereço para correspondência
}

\author{
Tomás Cebola \\ Av. da Independência \\ Caixa postal 606 - Tete, República de Moçambique \\ Alisson Barbieri \\ Cedeplar/Face/UFMG \\ Avenida Antônio Carlos, 6627, Pampulha \\ 31270-901 - Belo Horizonte-MG, Brasil \\ Gisela Zapata \\ Cedeplar/Face/UFMG \\ Avenida Antônio Carlos, 6627, Pampulha \\ 31270-901 - Belo Horizonte-MG, Brasil
}

\begin{abstract}
South-south migration: the recent wave of Zimbabwean immigration in Tete - Moçambique (2007-2016)
\end{abstract}

This article analyses the dynamics of international South-South migration through the case study of the recent immigration of Zimbabweans to the province of Tete, Mozambique, historically a region of emigration. We examine immigrants' socio-demographic characteristics, as well as the individual, family and structural conditions and motivations underlying this new migration flow. The analysis combines quantitative data from the 2007 Mozambican Census and administrative records for immigrant workers from the Provincial Directorate of Labour, Employment and Social Security, with semi-structured interviews with Zimbabwean immigrants in Tete. The results indicate a multiplicity of factors that contributed to the recent wave of immigration in Tete. In addition to economic and subsistence motivations, social and cultural aspects related to the long tradition of intra-regional mobility in Southern Africa, facilitated by relatively porous borders and strong cultural, linguistic and kinship ties, seem to be important. We also discussed how the installation of mining megaprojects with Brazilian capital in Tete, contributed to its appeal as a migrant destination, in a context in which violent waves of xenophobia against immigrants were occurring in South Africa, the main destination for migrants in the region.

Keywords: South-south migration. Immigration. Mozambique. Zimbabwe. Megaprojects. 


\section{Resumen}

Migraciones sur-sur: la reciente ola de inmigrantes zimbabuense en Tete - Mozambique (2007-2016)

El objetivo de este artículo es analizar la dinámica de la migración internacional sur-sur a partir del estudio de caso de la reciente inmigración de zimbabuenses a la provincia de Tete, Mozambique, históricamente una región de emigración. En este sentido, examinamos las características sociodemográficas de estos nuevos inmigrantes, así como las condiciones y motivaciones individuales, familiares y estructurales inherentes a este flujo migratorio. Para este fin, combinamos datos cuantitativos del censo de Mozambique de 2007 y registros de trabajadores inmigrantes de la Dirección Provincial de Trabajo, Empleo y Seguridad Social, con entrevistas semiestructuradas con inmigrantes zimbabuenses en Tete. Los resultados indican una multiplicidad de factores que contribuyeron a la reciente ola de inmigración en Tete, entre los que se destacan, además de las motivaciones económicas y de subsistencia familiar, aspectos sociales y culturales relacionados con la larga tradición de movilidad intrarregional en el sur de África, facilitada por fronteras relativamente porosas y por fuertes lazos culturales, lingüísticos y de parentesco. También discutimos cómo la instalación de megaproyectos mineros con capital brasileño en Tete contribuyó con su atractivo como destino migratorio, en un contexto en el que se asistía a violentas oleadas de xenofobia contra inmigrantes en Sudáfrica, el principal destino de las migraciones en la región.

Palabras clave: Migraciones sur-sur. Inmigración. Mozambique. Zimbabue. Megaproyectos.

Recebido para publicação em 20/06/2020 Aceito para publicação em 08/10/2021 